\title{
The effects of unilateral and bilateral medial thalamic lesions on discrimination learning in the rat
}

\author{
LARRY W. MEANS, RHONDA J. CLARK, GARY M. KING, and ANN E. WARING \\ East Carolina University, Greenville, North Carolina 27834
}

\begin{abstract}
Rats with bilateral medial thalamic lesions, unilateral medial thalamic lesions, and sham operations were tested on acquisition of a visual-tactile, compound stimulus, maze discrimination task. The animals with bilateral lesions were found to be deficient relative to the animals with either unilateral lesions or sham operations, while the latter two groups were not found to differ from each other.
\end{abstract}

It is now well established that bilateral lesions of the medial thalamus (MT) produce acquisition and retention deficits in rats on both appetitive (Means, Harrell, Mayo, \& Alexander, 1974; Means, Harrington, \& Miller, 1975; Means, Hershey, Waterhouse, \& Lane, 1975) and aversive tasks (see Delacour, 1971; Vanderwolf, 1971). Also, cats with bilateral lesions of the MT have been found to be deficient on escape (Mitchell \& Kaelber, 1967; Roberts \& Carey, 1963), and monkeys with MT lesions have been shown to be deficient on visual discrimination and delayed response tasks (Schulman, 1964).

Only Mitchell and Kaelber (1967) have investigated the effects of unilateral lesions of the MT in infrahumans. They report that unilateral lesions of the centromedian-parafasicular complex impair cats on retention of a two-way escape task when they are motivated by unilateral tooth pulp stimulation, regardless of whether the lesion is ipsilateral or contralateral to the tooth stimulated. However, they also found that cats are impaired when motivated by grid shock only after bilateral MT lesions. They suggest that the deficits are due to disruption of the pain system.

It is the purpose of the present study to examine the effects of unilateral lesions on acquisition of a task on which bilateral MT damaged rats are known to be deficient and which does not involve painful stimuli. Thus, rats with sham operations, unilateral MT lesions, and bilateral MT lesions were tested on acquisition of a visual-tactile maze discrimination, a task on which we have previously found bilaterally MT lesioned animals to be deficient (Means, Huntley, Anderson, \& Harrell, 1973; Waring \& Means, Note 1).

\section{METHOD}

\section{Subjects}

Thirty male Long-Evans rats from the East Carolina University colony, approximately 100 days of age at the beginning of the study, served as subjects. They were housed in individual cages with a 14-h light, 10-h dark cycle. The subjects were maintained at $85 \%$ of their ad-lib body weight throughout the experiment and had water available continuously.

\section{Apparatus}

Discrimination training was done in a previously described maze (Means, Huntley, Anderson, \& Harrell, 1973). The maze was equipped with guillotine doors to prevent retracing and had two interchangeable goalboxes, one having 25 -mm-wide black and white stripes and a smooth wooden floor and the other having a solid gray finish and a hardware cloth floor.

\section{Surgery and Histology}

Surgery was performed using $45 \mathrm{mg} / \mathrm{kg}$ sodium pentobarbital (Nembutal) for anesthesia. Each subject received $.20 \mathrm{ml}$ benzathine penicillin $\mathrm{G}$ (Bicillin), and animals with respiratory difficulties received $.20 \mathrm{ml}$ atropine sulfate. Lesions were made by passing $2.0 \mathrm{~mA}$ anodal current for $12 \mathrm{sec}$ through stereotaxically placed stainless steel electrodes, coated with Epoxylite except for the tip. The animals were mounted with the tooth bar $5.0 \mathrm{~mm}$ above the intraaural line. Corrdinates for the lesions were $1.2 \mathrm{~mm}$ posterior to bregma, $1.0 \mathrm{~mm}$ lateral to the midline, and $6.2 \mathrm{~mm}$ ventral to the dorsal surface of the skull. Coordinates for the sham animals were the same, except that the electrode was only lowered $5.0 \mathrm{~mm}$ ventral to the surface of the skull. Sham-operated subjects received no current.

Nine rats received bilateral lesions of the MT (B-MT), nine rats unilateral MT lesions (U-MT), and 12 rats unilateral sham operations (S). In the unilateral groups, surgery involved the left side for approximately half the subjects and the right side for half.

Following behavioral testing, the subjects were sacrificed with an overdose of Nembutal. The brains of the rats sustaining lesions were removed and sectioned at $50 \mu$ while frozen. Every fourth section was photographed using Kodak highcontrast copy film, and the negatives were projected onto plates from Pellegrino and Cushman's (1967) stereotaxic atlas, allowing determination of the locus and size of the lesions.

\section{Procedure}

Pretraining. Following surgery, the rats were allowed to recuperate for 14 days and then were handled for $30 \mathrm{~min}$ a day for 3 days. The animals were then given 5 days of maze adaptation which involved allowing the rats to explore the maze for $5 \mathrm{~min}$ or until they consumed 4 Noyes $.45-\mathrm{g}$ pellets in each goalbox, whichever occurred first.

Discrimination Acquisition. Discrimination training consisted of 10 trials per day, with an intertrial interval of approximately $10 \mathrm{~min}$. Correct choices were reinforced 

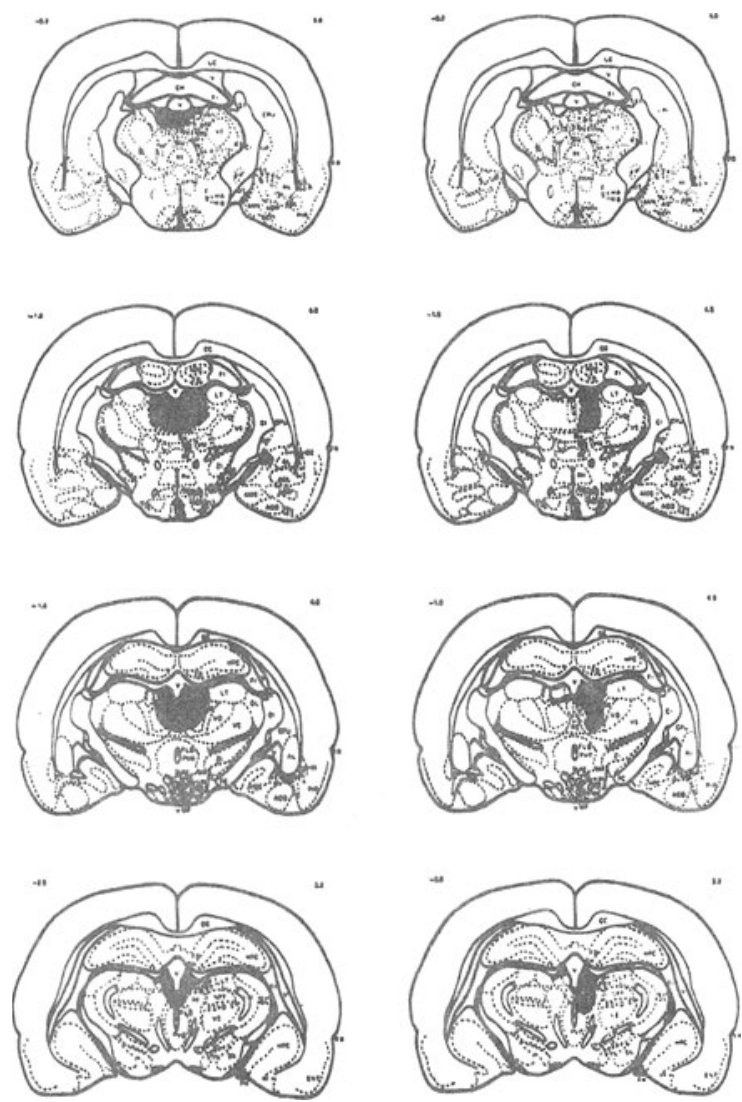

Figure 1. Reconstructions of a typical bilateral (left) and unilateral (right) lesion.

with four Noyes pellets. Approximately half of each of the three groups were trained to approach the striped, smooth floor goalbox and the other half to approach the gray, rough goalbox. The side of the reinforced choice was varied semirandomly, with the restrictions that the correct choice be on the left and right an equal number of times during each day of training, and not on the same side more than three times in a row. Training was terminated for each rat when it attained a criterion of 9 out of 10 correct choices on 3 consecutive days, with a minimum of 6 days training and a maximum of 15 days.

\section{RESULTS}

\section{Histological}

Typical unilateral and bilateral MT lesions are shown in Figure 1. The bilateral lesions are similar to those reported earlier (Means, Hunt, Whiteside, \& Bates, 1973; Means, Huntley, Anderson, \& Harrell, 1973). The lesions were centered on the dorsomedial nucleus, but bilaterally invaded several of the midline and MT nuclei. Also, the habenular complex was damaged in most animals. The unilateral lesions were similar to the bilateral lesions, except that they involved less tissue destruction and were essentially restricted to one hemisphere.

\section{Behavioral}

A summary of the acquisition data is presented in Table 1. Note that the subjects in the B-MT group made more errors and required more sessions to attain criterion than subjects in the $S$ and U-MT groups. In fact, six of nine subjects in Group B-MT never attained criterion during the 150 trials. All subjects in Groups S and U-MT attained criterion. A Kruskal-Wallis analysis of variance revealed that the three groups differed significantly on the number of errors to criterion $(\mathrm{H}=67.76, \mathrm{df}=2, \mathrm{p}<.001)$. Further, Mann-Whitney tests revealed that the B-MT groups differed significantly from both the $\mathrm{S}$ and U-MT groups $(\mathrm{p}<.05$ in both cases) and that the $S$ and U-MT groups did not differ from each other. An analysis of the sessions to criterion on the original acquisition produced almost exactly the same results as the analysis based on errors to criterion. A Kruskal-Wallis test revealed that the three groups differed significantly $(H=46.99$, df $=2$, $\mathrm{p}<.001)$ on sessions to criterion, and Mann-Whitney follow-up tests revealed that the B-MT group differed from the $S$ and U-MT groups ( $p<.05$ in both cases), which did not differ from each other. Thus, on both errors and sessions to criterion the B-MT did significantly worse than the S and U-MT groups, and on both measures the $\mathrm{S}$ and U-MT groups did not differ from each other.

Another observation that can be made from Table 1 is that the bilateral MT lesions resulted in tremendous variability in performance. While most animals in Group B-MT were severely impaired, three animals made 13 or fewer errors during acquisition. Unilateral lesions did not produce greater variability of performance than was observed in the $S$ rats. Histological examination revealed no consistent lesion differences between animals making relatively few or large numbers of errors.

\section{DISCUSSION}

While our previously reported observation that rats with bilateral MT lesions are deficient on acquisition of visualtactile discrimination (Means, Huntley, Anderson, \& Harrell, 1973) was replicated, we found no evidence that unilateral lesions produce a deficit on visual-tactile discrimination. Thus, while many studies have shown that bilateral destruction of the MT impairs acquisition (Delacour, 1971; Means et al., 1973; Vanderwolf, 1971), it appears that the MT need only be intact unilaterally for normal acquisition of a two-choice discrimination. Apparently, the bilateral afferent and efferent

Table 1

Median and Range Number of Errors and Sessions to Criterion

\begin{tabular}{|c|c|c|c|c|c|c|}
\hline & \multicolumn{2}{|c|}{$\begin{array}{l}\text { Group } S \\
(n=12)\end{array}$} & \multicolumn{2}{|c|}{$\begin{array}{c}\text { Group U-MT } \\
(\mathrm{n}=9)\end{array}$} & \multicolumn{2}{|c|}{$\begin{array}{c}\text { Group B-MT } \\
(\mathrm{n}=9)\end{array}$} \\
\hline & Errors & Sessions & Errors & Sessions & Errors & Sessions \\
\hline $\begin{array}{l}\text { Median } \\
\text { Range }\end{array}$ & $\begin{array}{r}9.0 \\
4-16\end{array}$ & $\begin{array}{l}5.5 \\
5-7\end{array}$ & $\begin{array}{r}9.0 \\
8-25\end{array}$ & $\begin{array}{l}6.0 \\
5-8\end{array}$ & $\begin{array}{l}44.0 \\
8-72\end{array}$ & $\begin{array}{l}15.0 \\
6-15\end{array}$ \\
\hline
\end{tabular}


connections of the MT (Leonard, 1972) make it possible for either side of the thalamus to mediate the MT functions necessary for acquisition of a discrimination task. It should be pointed out that the discrimination task used in the present experiment involves both bilateral sensory input and a bilateral response. Recalling Mitchell and Kaelber's (1967) deficit in cats with unilateral MT lesions on escape from a unilateral shock, it would be interesting to examine the effects of unilateral MT lesions on an appetitive task involving a unilateral stimulus and/or response. The many studies demonstrating deficits in animals with bilateral MT lesions on appetitive tasks reveal that the MT does more than mediate pain.

\section{REFERENCE NOTE}

1. Waring. A. E., \& Means, L. W. In preparation.

\section{REFERENCES}

Delacour, J. Effects of medial thalamic lesions in the rat: A review and interpretation. Neuropsychologia, 1971, 9, 157-174.

LEONARD, C. M. The connections of the dorsomedial nuclei. Brain. Behavior and Evolution, 1972, 6, 524-541.

Means, L. W., Harrell, T. H., Mayo, E. S., \& Alexander, G. B. Effects of dorsomedial thalamic lesions on spontaneous alternation, maze activity, and runway performance in the rat. Physiology and Behavior, 1974, 12, 973-979.

Means, L. W., Harrington, J. H., \& Miller, G. T. The effect of medial thalamic lesions on acquisition of a go, no-go, tone-light discrimination task. Bulletin of the Psychonomic Society, 1975, 5, 495-497.

Means, L. W., Hershey, A. E., Waterhouse, G. J., \& LANE, C. J. Effects of dorsomedial thalamic lesions on spatial discrimination reversal in the rat. Physiology and Behavior, 1975, 14, 725-729.

Means, L. W., Hunt, M. W., Whiteside, R. R., \& Bates, T. W. Deficient acquisition and retention of single-alternation go, no-go rats with medial thalamic lesions. Physiological Psychology, 1973, 1, 287-291.

Means, L. W., Huntley, D. H., Anderson, H. P., \& Harrell, T. H. Deficient acquisition and retention of a visualtactile discrimination task in rats with medial thalamic lesions. Behavioral Biology, 1973, 9, 435-450.

Mitchell, C. L., \& KaElber, W. W. Unilateral vs. bilateral medial thalamic lesions and reactivity to noxious stimuli. A rchives of Neurology, 1967, 64, 256-261.

Pellegrino, L. J., \& Cushman, A. J. A stereotaxic atlas of the rat brain. New York: Appleton-Century-Crofts, 1967.

Roberts, W. W., \& CAREY, R. J. Effect of dorsomedial thalamic lesions on fear in cats. Journal of Comparative and Physiological Psychology, 1963, 56, 950-958.

Schulman, S. Impaired delayed response from thalamic lesions. Studies in monkeys. Archives of Neurology, 1964, 11. 477-499.

VANDERWOLF, C. H. Limbic-diencephalic mechanisms of voluntary movement. Psychological Review, 1971, 78, 83-113.

(Received for publication October 20, 1975.) 